Produto \& Produção, vol. 15 n.2, p. 46-65 jun. 2014

RECEBIDO EM 12/06/2013. ACEITO EM 10/03/2014.

\title{
O setor produtivo de eletroeletrônicos e a logística reversa de seus produtos pós- consumo
}

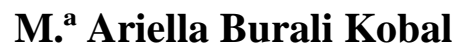 \\ Universidade Federal do Ceará - UFC \\ Mestra em Administração e Controladoria \\ ariellaburali@yahoo.com.br
}

Dra. Sandra Maria dos Santos

Vice-diretora da Faculdade de Economia, Administração, Atuárias e Contabilidade - FEAAC da Universidade Federal do Ceará e professora associada da UFC

smsantos@ufc.br

\section{Dr. José Carlos Lázaro}

Coordenador do departamento de Administração da Faculdade de Economia, Administração, Atuárias e Contabilidade - FEAAC e Professor Adjunto da Universidade Federal do Ceará lazaro.ufc@gmail.com

\author{
Dr. Augusto Cézar de Aquino Cabral \\ Diretor da Faculdade de Economia, Administração, Atuárias e Contabilidade - FEAAC da \\ Universidade Federal do Ceará e Professor da Universidade Federal do Ceará \\ cabral@ufc.br
}

\section{RESUMO}

O Brasil encontra-se atualmente entre os onze países em desenvolvimento que mais produz resíduos eletroeletrônicos, cerca de 2,6 quilos/ano por habitante. Diante desse cenário, este trabalho teve como objetivo geral analisar de que forma a indústria produtiva de eletroeletrônico têm atuado na cadeia e na logística reversa desses resíduos. Trata-se de uma pesquisa quantitativa, de natureza exploratória e descritiva. As fontes primárias deste estudo provêm da aplicação de survey em 252 empresas do setor de eletroeletrônico cadastradas na Associação Brasileira da Indústria Elétrica e Eletrônica. Concluiu-se que o setor desenvolve ações de eco-design e avaliação do ciclo de vida do produto e embora a parceria entre este setor e o setor de resíduos eletroeletrônico tenha sido evidenciada, a mesma é tímida e necessita ser estimulada a fim de ampliar a oferta de matéria prima para o setor de resíduos fortalecendo ações de coleta e redução desses resíduos a nível nacional.

Palavras Chaves: Eco- Design. Avaliação do Ciclo de Vida do Produto. Resíduos Eletroeletrônicos. 


\begin{abstract}
The Brazil is among the eleven developing countries that produce more electronic waste in the world, about 2.6 kilos / year per inhabitant. In face of this fact, this study aimed to examine how the productive industry of electronics have been active in the chain and reverse logistics such waste This is a quantitative, exploratory and descriptive survey. The primary sources of this study are derived from survey of 252 companies in the electronics registered at the Brazilian Association of Electrical and Electronics Industry. It was concluded that the sector develops programs in eco - design and life cycle assessment of the product and although the partnership between the industry and the electronics industry waste has been demonstrated, it is shy and needs to be stimulated in order to increase the supply of raw material for waste sector strengthening actions and collection of these waste reduction at the national level.
\end{abstract}

Key Words: Eco-Design. Life Cycle Assessment of Products. Electric and Electronic Waste

\title{
1. Introdução
}

A indústria brasileira de eletroeletrônico reúne cerca de 4.000 empresas, sendo $80 \%$ delas de pequeno porte com menos de 100 colaboradores. Trata-se de um setor de capital intensivo gerando cerca de 180 mil empregos diretos, tendo atingido em 2011 um faturamento de 80 bilhões de dólares, representando cerca de 3,5\% do PIB brasileiro (ABINEE, 2012).

No Brasil, o setor produtivo de eletroeletrônico é representado desde 1963 pela Associação Brasileira da Indústria Elétrica e Eletrônica - ABINEE. A mesma possui como associadas cerca de 650 indústrias de capital nacional e internacional, dos mais diversos portes e segmentos diferentes. A perspectiva para o crescimento do faturamento do setor em 2013 é de $8 \%$ alcançando as cifras de $\mathrm{R} \$$ 155,7 bilhões com incremento em todas as áreas, evidenciando um aumento no consumo também nas áreas de informática, componentes elétricos e eletrônicos e telecomunicações, (ABINEE, 2013).

Estudos indicam que o Brasil em 2014 deve gerar em torno de 1.100 mil toneladas de resíduos de equipamento eletroeletrônicos podendo chegar a 1.247 mil toneladas em 2015, e os 150 maiores municípios brasileiros, a maioria deles das regiões sul e sudeste do país, são responsáveis por aproximadamente dois terços de todo resíduo eletroeletrônico que se estima seja descartado no Brasil (MDIC, 2014).

Esse crescimento no consumo atesta a necessidade de indústrias para coleta e reciclagem do resíduo desses produtos. Algumas indústrias estimuladas por Resoluções como, por exemplo, as indústrias de pilhas, baterias e pneus, encontra-se com uma estrutura mais coesa no tocante a coleta e destino responsável dos resíduos. O mesmo não acontece com os resíduos eletroeletrônicos (KOBAL, 2013).

A gestão ambiental na indústria eletroeletrônica é relativamente recente, e o foco das pressões ambientais deixa de ser a gestão ambiental da produção e passa a ser a gestão ambiental do produto, ou seja, a durabilidade do produto, a possibilidade de reciclagem do mesmo, o tipo de matéria prima usado, a facilidade de desmonte e reaproveitamento, o tipo de embalagem e seu processo de reciclagem, são todos fatores considerados, visando um menor impacto ambiental depois de seu consumo.

A fim de minimizar estes impactos ambientais e servir de base à identificação de oportunidades para a melhoria do desempenho ambiental de produtos em diversos pontos de seu ciclo de vida, é lançado em 2010 o Programa Brasileiro de Avaliação do Ciclo de Vida- PBACV objetivando disponibilizar e disseminar a metodologia de elaboração dos inventários de impacto ambiental. A medida busca implantar no país um sistema de avaliação dos impactos ambientais na produção e consumo de bens e serviços. Tal metodologia é reconhecida internacionalmente e é usada como base de critérios de importação por alguns países, pois o inventário de ciclo de vida contém estudos sobre consumo e liberação de energia e substâncias químicas na água, na terra e no ar. 
Kobal et. al (2013) afirmam que os impactos ambientais gerados pelos resíduos eletroeletrônicos vem despertando a sociedade, empresários e ambientalistas de tal forma que tais resíduos entraram na pauta da Política Nacional de Resíduos Sólidos que os traz em sua concepção a responsabilidade compartilhada e a logística reversa, que compete também ao setor produtivo de eletroeletrônico. A lei tem gerado debates frente algumas dificuldades identificadas pelo setor de eletroeletrônico entre elas a entrada irregular e ilegal de produtos eletroeletrônicos. De acordo com a visão do setor a responsabilidade pela logística reversa e destinação correta dos produtos eletroeletrônicos que entram no país dessa forma - os chamados lixos cinza ou resíduos eletrônicos cinza - cabe ao poder público cuja omissão permitiu a entrada dos mesmos (ABINEE, 2012).

A cadeia do eletroeletrônico no Brasil é complexa, o setor de eletroeletrônicos é formado por indústrias nacionais e internacionais, é um grande complexo eletrônico quando se considera o conjunto de segmentos baseado em microeletrônica que guarda vínculos importantes para praticamente todo o sistema econômico. O setor conta ainda com matéria prima nacional e internacional para poder produzir. A indústria internacional abastece o setor com todos os componentes microeletrônicos, enquanto a indústria nacional projeta o produto (CERTI, 2005).

Depois de distribuído e comercializado, estes produtos deverão retornar a cadeia no fim de sua vida útil, e o setor que os absorverá será o de resíduos eletroeletrônicos que no Brasil segundo Kobal et.al (2013) é formado por um número pequeno e insuficiente de empresas.

A pesquisa se justifica por causa do aumento de consumo de produtos eletroeletrônicos e consequentemente seus resíduos e devido a uma pesquisa anterior feita com três empresas de resíduos eletroeletrônicos de três diferentes estados brasileiros onde se observou algumas dificuldades enfrentadas por este setor, porém, a que mais intrigou foi ter identificado falta de matéria prima e capacidade instalada ociosa na produção, além do fato das empresas produtivas de eletroeletrônicos não terem sido citadas por nenhuma das três empresas de resíduos entrevistadas como um elo parceiro na logística reversa (KOBAL, 2013).

Se o consumo de eletroeletrônico só aumenta, a produção desses produtos no Brasil cresce anualmente e consequentemente seus resíduos, a matéria prima para o setor de resíduos eletroeletrônico não deveria ser um problema.

Estes pontos em especial serviram de estímulo e desafio para essa pesquisa. Durante este processo, encontrou-se dois estudos sobre o setor produtivo de eletroeletrônico brasileiro o de Jabbour e Jabbour (2012) e Arenhardt, Battistella e Franchi (2012) que identificaram características de cadeia de suprimento verde no setor, em especial a preocupação dessa industria com o design verde e com a Avaliação do Ciclo de Vida do Produto - (ACV). Cadeia de suprimento verde, eco- design, avaliação do ciclo de vida do produto e logística reversa são os temas que regem este estudo.

O problema de pesquisa é: De que forma a indústria produtiva de eletroeletrônico têm atuado na cadeia e na logística reversa desses resíduos?

Parte-se do pressuposto que: a) A cadeia produtiva do eletroeletrônico não é parceira da cadeia produtiva do setor de resíduos eletroeletrônicos. b) O setor produtivo de eletroeletrônico desenvolve a avaliação do ciclo de vida do produto, aplica eco-design na elaboração dos mesmos e mantém uma logística reversa possuindo características de cadeia de suprimento verde.

Tem como objetivo geral analisar de que forma a indústria produtiva de eletroeletrônico têm atuado na cadeia e na logística reversa desses resíduos. E como objetivos específicos: $1^{\circ}$ Verificar as características da cadeia de suprimento da indústria eletroeletrônica e a parceria com o setor de resíduos eletroeletrônicos. $2^{\circ}$ Identificar as ações verdes do setor produtivo do eletroeletrônico na perspectiva do Design Verde, da Avaliação do Ciclo de Vida e da logística reversa.

\section{Fundamentos Teóricos}

\subsection{Cadeia de suprimento}

Beamon (1999) diz que a cadeia de suprimento tem sido tradicionalmente definida como uma cadeia one-way, com processo de produção integrada em que as matérias-primas são convertidas em produtos finais, em seguida, entregue aos clientes. Sob esta definição, a cadeia de suprimentos inclui apenas as atividades associadas com a fabricação, desde a aquisição de matéria- 
prima até a entrega do produto final. No entanto, devido à recente mudança e exigências ambientais afetando as operações de fabricação, uma crescente atenção vem sendo dada a gestão ambiental e consequentemente ao desenvolvimento de estratégias para a cadeia de suprimento.

Visando o desenvolvimento de novas estratégias para a cadeia de suprimento ocorreu uma reestruturação na cadeia de valor das organizações na busca por processos capazes de gerar vantagens competitivas. Nessa busca o foco deixou de estar apenas na gestão dos processos internos das organizações e se voltou também para a integração de fornecedores e demais agentes que compõe suas cadeias de suprimento. A gestão da cadeia de suprimento será determinada "pela complexidade das situações existentes, relacionadas ao tipo de produto, número de fornecedores, disponibilidade das matérias-primas, bem como o tipo de gerenciamento e a extensão deste sobre a cadeia" (NEUTZLING 2012, p. 24).

Corrêa (2010) considera a cadeia de suprimento como uma fonte real e importante de vantagens competitivas sustentáveis, pois segundo ele a concorrência pelos mercados se dá entre cadeias de suprimento e não mais entre empresas. O referido autor explica que o fornecedor troca bens e informações com o fabricante que por sua vez faz o mesmo com o distribuidor que realiza o mesmo procedimento com o varejista.

O desafio de todo esse processo consiste em redefinir a estrutura básica da cadeia de suprimento e inserir nela preocupações ambientais, que surgem impulsionadas por pressões da sociedade e da legislação fazendo com que a indústria e os seus elos envolvidos, iniciem um procedimento de medidas em sua cadeia de suprimento visando melhorias em todos os seus processos com vistas a um resultado final que gere menor impacto ambiental.

\subsection{Cadeia de suprimento verde}

Segundo Srivastava (2007, p. 54) existem várias facetas e aspectos sendo discutidos por diferentes pesquisadores sobre o conceito da Gestão da Cadeia de Suprimento Verde (GSCM). Ele a define como:

A integração do pensamento ambiental na gestão da cadeia de suprimentos, no design de produtos, incluindo material, terceirização e seleção, nos processos de fabricação, na entrega do produto final aos consumidores, bem como na gestão de vida do produto e após a sua vida útil. (tradução nossa)

Em sua pesquisa Srivastava (2007) identificou que a literatura sobre a GSCM a classificava em três grande categorias: a importancia da GSCM; o design verde e as operações verdes elaborando a partir dessas categorias um framework de classificação baseada no contexto do problema de design da cadeia de suprimento verde. 


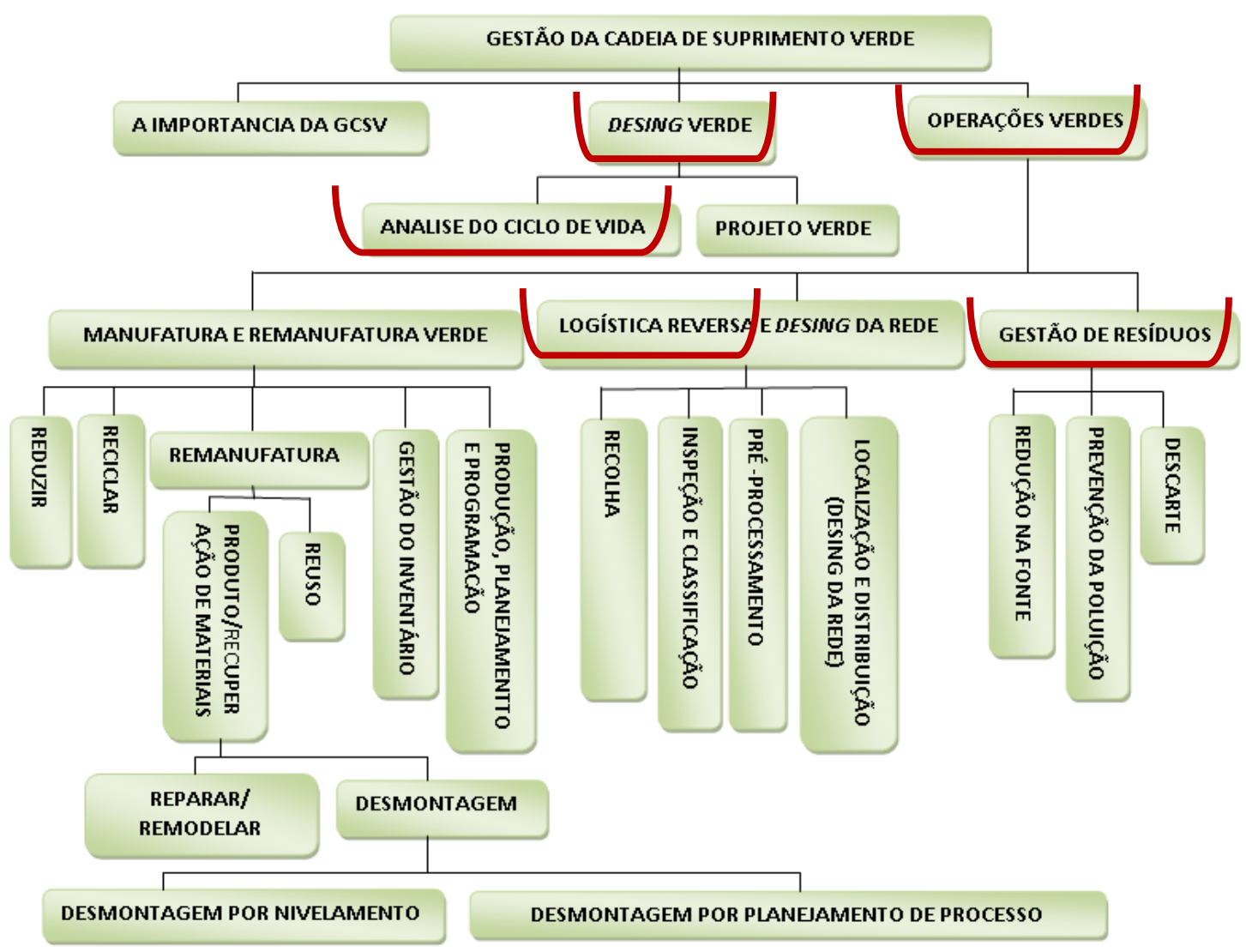

Figura 1- Classificação baseada no design da cadeia de suprimento verde. Fonte: Srivastava (2007, p.55)

Na proposta de Srivastava (figura 1) em relação a "importancia da GCSV" o autor aborda a parte teórica da gestão da cadeia de suprimento verde, os conceitos encontrados na literatura e concentra-se na sua necessidade e na sua importancia, sugerindo fundamentos de greening como uma iniciativa competitiva a exemplo de compras ecológicas, ecologia industrial e ecossistemas industriais, pois visa gerar economia de recursos, eliminação de desperdícios e aumento de produtividade.

O "Design Verde" ou eco-design inclui o projeto verde, que visa pensar o produto/processo do ponto de vista de projeto consciente ao ambiente, considerando o ciclo de vida e a análise do ciclo de vida- ACV.

Embora o modelo de Srivastava (2007) apresentado na figura 1, aborde vários tópicos, dentro da proposta deste trabalho serão analisadas apenas os estudos do Design Verde com a abordagem do Ciclo de Vida de Produto, e dentro das Operações Verdes será explorado a Gestão de Resíduos e a Logística Reversa.

Com foco na adoção de práticas de gestão da cadeia de suprimento verde- (GSCM), a pesquisa de Jabbour e Jabbour (2012) traça um perfil das empresas de eletroeletrônicos através de algumas variáveis agrupadas em três fatores: "GSCM orientada aos fornecedores", "GSCM orientada aos consumidores" e "GSCM orientada à recuperação de investimentos" e concluem que as empresas adotam algumas práticas de gestão ambiental encontradas nas características de uma cadeia de suprimento verde, e demonstram que embora de forma moderada e positiva há uma relação entre a gestão ambiental e a adoção das práticas de GSCM.

Arenhardt, Battistella e Franchi (2012) em sua pesquisa, identificaram a partir dos constructos inovação de produtos verdes e inovação de processos verdes, práticas de inovação verde no setor de eletroeletrônico brasileiro, cujas variáveis analisadas remontam a características encontradas em uma gestão da cadeia de suprimento verde, em especial no quesito design verde ou eco-design.

\subsubsection{Eco-desin ou Design verde.}


Corroborando com Srivastava (2007) quando o mesmo fala sobre o projeto verde do ecodesign, Karlsson e Luttropp (2006, p. 1291) definem Eco-Design como um conceito que integra aspectos multifacetados de design e considerações ambientais, para os autores

Eco-Design é um conceito de sustentabilidade, incluindo as prioridades humanas, juntamente com relações de negócios. Seu principal objetivo está na melhoria de métodos para o desenvolvimento de produtos e redução dos impactos ambientais. Também inclui uma ambição ainda maior, a de usar a inspiração de campo dos exemplos positivos, de produtos inteligentes e métodos além de soluções de sistemas eficazes e desenhos atraentes. (tradução nossa)

Mais importantes do que as ferramentas de concepção ecológicas são as especificações e definições de metas nas fases iniciais do desenvolvimento dos produtos. É crucial organizar o desenvolvimento do produto para alcançar graus mais elevados de sustentabilidade e as inter-relações entre os recursos e a funcionalidade deve ser reforçada. A afeição ambiental deve ser integrada durante todo o ciclo de vida de todos os produtos e serviços. Essa integração das questões ambientais no desenvolvimento do produto, deve considerar as avaliações ambientais que podem ser feitas a partir de uma perspectiva externa, introduzindo por exemplo, as prioridades ambientais regidas por leis e normas (KARLSSON; LUTTROPP, 2006).

Pigosso et.al. (2010) afirmam que para implementar com sucesso modelos de negócios sustentáveis, é necessário promover uma mudança nos valores econômicos para apoiar a abordagem do pensamento do ciclo de vida do produto, devido a escassez de matérias primas, a limitação do ambiente em absorver resíduos e emissões e as necessidades de consumo de uma população crescente. E o eco-design na perspectiva do fim da vida do produto é estruturado estrategicamente de acordo com as necessidades econômicas, ambientais e sociais locais, compreendendo a redução do impacto ambiental no descarte dos produtos.

A fim de melhorar o desempenho ambiental, cada produto requer medidas específicas dependendo de seu impacto ambiental nas diferentes etapas do seu ciclo de vida. Medidas distintas e apropriadas de Eco-design devem ser tomadas visando um menor impacto ambiental nas etapas de desenvolvimento, fabricação, e uso dos produtos. Tais medidas habilitam a empresa a melhorar os produtos já existentes e aqueles em elaboração. Estas são divididas em cinco etapas: a materia prima, o processo produtivo, a logística, o uso intensivo dessas medidas e a melhoria do impacto ambiental (INSTITUT FÜR KONSTRUKTIONSWISSENS, 1996).

O modelo apresentado pelo Institut Für Konstruktionswissens (1996) é corroborado por Schroeder, Goldstein e Rungtusanatham (2011) ao afirmarem que a atenção com o impacto ambiental é uma tarefa estratégica, e deve ser concebida como parte da estratégia de negócios.

Schroeder, Goldstein e Rungtusanatham (2011) explicam que em uma cadeia de suprimentos verde a empresa deve examinar todas as oportunidades, incluindo desenvolvimento de produtos, terceirização, fabricação, embalagem, distribuição, transporte, serviços e a gestão do ciclo de vida do produto. Se a estratégia já estiver definida então o melhor será começar com algumas iniciativas conforme segue:

1. Eliminar o ar, água e poluição do aterro;

2. Reduzir o consumo de energia;

3. Medir e minimizar o transporte e a pegada de carbono total;

4. Trabalhar com os fornecedores e usar embalagens recicláveis e biodegradáveis;

5. Incorporar reutilização do produto, de retorno de vida e de reciclagem.

Considerando a extensão de cada iniciativa, os autores afirmam que, o mais importante é iniciar com a medição do impacto ambiental em qualquer uma dessas áreas, ou em todas elas, o critério para a escolha estará no perfil da empresa, ou na atividade que mais produz impacto ambiental segundo a empresa (SCHROEDER; GOLDSTEIN; RUNGTUSANATHAM, 2011).

Sarkis (2003) explica que um fator estratégico que influencia a gestão da cadeia de suprimentos é o acompanhamento do ciclo de vida dos produtos principalmente a partir da fase de 
declínio do produto no mercado, onde a logística reversa impactará nas práticas ambientais das organizações.

A cadeia de suprimento sob a perspectiva ambiental se operacionaliza com a adoção do conceito do ciclo de vida do produto, para tanto, faz-se necessário identificar e quantificar os impactos ambientais ao longo da cadeia, ou seja, além de considerar as etapas envolvidas no processo de produção, distribuição e uso, considerar também as etapas dos fluxos reversos associados à recuperação de materiais processados ou usados para reaproveitá-los novamente (SHEU, 2005; SCHROEDER; GOLDSTEIN; RUNGTUSANATHAM, 2011; BARBIERI; CAJAZEIRA; BRANCHINI, 2009).

O estudo e a aplicação do ciclo de vida do produto são importantes por tratar-se de um fator estratégico para a gestão da cadeia de suprimento e por facilitar a quantificação dos impactos ambientais ao longo dessa cadeia.

\subsubsection{Avaliação do Ciclo de Vida do Produto.}

Pigosso et.al. (2010) explicam que o conceito de ciclo de vida do produto é a integração das perspectivas do ciclo de vida para a estratégia geral de planejamento e processos decisórios de uma organização, tendo em conta considerações econômicas, sociais e ambientais. A introdução desse conceito está associada a esforços para aumentar a eficiência ao longo do ciclo de vida do produto, alargando as responsabilidades das partes envolvidas. Assim, o principal desafio é para que as organizações considerem o ciclo de vida do produto completo, com foco na otimização das interações entre design de produto, processos de fabricação e outras atividades do ciclo de vida, incluindo o uso e tratamento no fim de vida desse produto.

O estudo do ciclo de vida do produto surge segundo Donato (2008, p. 96), "com a consciência de que qualquer produto, processo ou atividade produz impactos no ambiente" desde a extração da sua matéria prima até o esgotamento da sua vida útil, quando o produto é devolvido à natureza. $\mathrm{O}$ autor explana sobre a importância da análise do ciclo de vida do produto e apresenta a Avaliação de Ciclo de Vida- ACV como uma ferramenta para a análise das relações entre os sistemas produtivos e o ambiente e afirma que "a aplicação da ACV à atividade logística é relativamente nova e complexa".

"A Avaliação do Ciclo de Vida - ACV é um instrumento de gestão ambiental aplicável a bens e serviços e a norma ISO 14040 define o ciclo de vida como estágios consecutivos e interligados de um sistema de produto" (BARBIERI 2007, p. 164). A norma define o ciclo de vida desde a extração dos recursos naturais, incluindo a aquisição da matéria prima até a disposição final.

Há uma variedade de conceitos e métodos adotados por governos e entidades sobre a ACV cujas avaliações feitas segundo critérios diferentes geram resultados diferentes sobre os impactos ambientais de um mesmo produto, desacreditando esse instrumento ambiental (ACV). A ISO 14040 busca dar credibilidade ao instrumento no momento em que estabelece conceitos, diretrizes e requisitos para $\mathrm{ACV}$, sendo uma ferramenta reconhecida também no comércio internacional (BARBIERI, 2007).

Barbieri e Cajazeira (2009, p. 3), explicam o ciclo de vida física de um bem ou serviço. Para os autores o ciclo de vida abrange estágios do processo de produção e comercialização

Desde a origem dos recursos naturais no meio ambiente, até a disposição final dos resíduos de materiais após o uso, passando pelo beneficiamento, transportes, estocagens, processamento, manutenção e outros estágios intermediários. Por isso, esse conceito também é conhecido pela expressão do berço ao túmulo (cradle to grave), o berço é o meio ambiente de onde são extraídos os recursos naturais que serão transformados e o túmulo é o próprio meio ambiente enquanto destino final dos resíduos de produção e consumo que não foram reusados ou reciclados pelos sistemas produtivos.

Também fazem parte do ciclo de vida os transportes entre uma etapa e outra, bem como dentro delas, incluindo os retornos de materiais para reuso, reparo, reciclagem e a remoção dos resíduos. Fazse necessário conhecer os impactos ambientais específicos de cada etapa da cadeia produtiva para a busca por redução na extração de recursos naturais e nos lançamentos de resíduos não aproveitados. 
Os problemas ambientais são transferidos de uma etapa a outra e não podem ser resolvidos de maneira adequada por uma única unidade produtiva de forma isolada. Essa visão do ciclo do ciclo de vida "permite atuar com mais eficácia tanto sobre os problemas ambientais dos produtos e serviços existentes, quanto sobre a concepção e implementação de inovações de produtos e processos produtivos". Tais ações objetivam reduzir os resíduos antes de serem gerados e facilitam a recuperação de materiais após o uso do produto (BARBIERI; CAJAZEIRA 2009, p. 4).

Barbieri e Cajazeira (2009) trazem um framework que corrobora com o modelo de Sarkis (2003) quando mostra o impacto que o ciclo de vida do produto traz ao meio ambiente a partir do momento que o mesmo utilizará energia, materiais, água, e uso do solo para sua elaboração. Todos esses elementos da natureza estão contidos segundo os autores em cinco momentos chaves: a extração e processamento de matérias primas; que servirá de base para a manufatura dos produtos; que serão enviados a distribuição depois de elaborados; usados e consumidos num quarto momento e terminarão na gestão desses resíduos consumidos.

Cada uma das etapas gerará consumo de energia e resíduos que seguirão para disposição final, ou seja, o descarte. Após o uso e consumo a gestão desses resíduos buscará estender o ciclo de vida desses produtos consumidos, a fim de minimizar os impactos ambientais, reenviando-os através de reuso para a distribuição ou diretamente ao usuário, ou reciclando e reenviando-o para a manufatura de produtos que gerará outro produto, ou depois da reciclagem de volta a distribuição e para fechar corretamente o ciclo do produto a gestão dos resíduos enviará ao descarte tudo o que não houver condições de reaproveitamento

De acordo com os autores supracitados, uma cadeia que considera o conceito de ciclo de vida (life cycle thinking) faz uso sistemático de instrumentos de gestão decorrentes desse pensamento, entre eles está a Avaliação do Ciclo de Vida (ACV) e é considerado o mais importante por permitir conhecer os impactos ambientais do produto ou serviço ao longo da cadeia.

"O gerenciamento do ciclo de vida é importante para as mais simples ações e podem resultar em efetivas melhorias na eficiência do uso de recursos, e na prevenção da poluição" (MAGALHÃES 2010, p. 49).

Embora o conceito de ciclo de vida esteja voltado à cadeia produtiva, Barbieri e Cajazeira (2009), afirmam que sua operacionalização se dá na cadeia de suprimento e que a logística é parte do processo de gerenciamento dessa cadeia. Essa afirmação pode ser corroborada ao se observar o modelo de framework de Sarkis (2003, p. 400) que também considera a energia consumida e os resíduos produzidos durante todo o processo produtivo incluindo o retorno, o reuso, a e reciclagem desses produtos.

Entretanto para Sheu, Chou e Hu (2005), apesar da importância da cadeia de suprimento verde como ecologia industrial, ainda é crítica a integração dessa cadeia verde e da logística sob o ponto de vista estratégico organizacional. Para que a cadeia esteja realmente voltada para os impactos ambientais produzidos por ela, a logística, em especial a reversa, deve estar integrada de forma sistêmica aos processos e resultados, principalmente no quesito gestão de resíduos e retorno dos produtos.

Os autores apontam algumas dificuldades entre elas a coordenação das atividades de todos os membros da cadeia, incluindo os produtos orientados para os canais de logística de distribuição e os canais da logística reversa. As metas operacionais entre os membros da cadeia podem entrar em conflito, quando a maximização de lucros de um membro da logística reversa não necessariamente maximiza os lucros de um fabricante da cadeia de suprimento. Há ainda a falta de modelos adequados de gerenciamento da logística dos fluxos associados a cada membro da cadeia visando a otimização do processo de gestão da cadeia de suprimento verde. Também há falta de comprometimento do cliente final no tocante a vontade de retornar os produtos utilizados, além de outros fatores externos tais como as políticas e regulamentações governamentais, que influenciam o desempenho do abastecimento de uma cadeia de suprimento verde, em especial aos canais de distribuição para a logística reversa (SHEU; CHOU; HU, 2005).

\subsection{A Logistica Reversa}

Para Leite, Lavez e Souza (2009), a preocupação crescente com o meio ambiente vem tornando importante a reutilização dos materiais e a formação de um ciclo que parte do consumidor e 
chega novamente ao fornecedor. O gerenciamento inverso desses materiais, apoiado pelo fluxo direto da cadeia de suprimento, é sustentado pela logística reversa.

Armazenar, transportar, distribuir são conceitos logísticos sólidos, entretanto para Magalhães (2010) o inverso dessa logística é tão novo como a busca por soluções ao aumento do consumo pela sociedade. Atividades como reciclagem e reaproveitamento de produtos e embalagens tem levado a logística reversa a crescer.

Segundo Sarkis (2003) e Donato (2008), entre as funções operacionais, a logística reversa é a menos desenvolvida e estudada dentre todas. Sob uma perspectiva ambiental a logística reversa concentra principalmente o retorno dos recicláveis ou produtos reutilizáveis e materiais na cadeia de abastecimento para frente. Também pode ser estudada a partir da perspectiva de itens devolvidos sob garantia que podem até não terem sido usados.

Nhan, Souza e Aguiar (2003) e Donato (2008) definem a logística reversa como a logística de fluxo reverso, ou seja, do ponto de consumo até o ponto de origem. Afirmam que em função do aumento das atividades de reciclagem e reaproveitamento de produtos e embalagens cujo consumo aumentou consideravelmente nos últimos anos, a logística reversa vem crescendo.

Para Leite (2009) a logística reversa possui canais de distribuição reversos classificados como canais reversos de pós-consumo e canais reversos de pós venda. O mesmo afirma que os bens industriais duráveis ou semiduráveis após o descarte tornam-se produtos de pós consumo, que quando apresenta condições de utilização podem ser destinados ao mercado de segunda mão e ser por diversas vezes comercializados até o fim de sua vida útil.

A importância estratégica alcançada com a logística reversa fez despertar o interesse por essa ferramenta. Muitas empresas que antes não despendiam tempo nem energia a compreensão desse processo mudaram seus valores a tal ponto, que algumas buscam certificação ISO em seus processos de retorno, e terceirizados têm visto um grande aumento na demanda por seus serviços (ROGERS e TIBBEN-LEMBKE, 1998)

Liva, Pontelo e Oliveira (2003), abordam alguns aspectos de negócios ao qual a logística reversa está relacionada tais como proteção ao meio ambiente quando busca uma redução nos resíduos, diminuição dos custos - com o retorno de materiais ao ciclo produtivo, melhora da imagem da empresa perante o mercado, relação custo benefício vantajosa e aumento significativo nos lucros da empresa com a reutilização de materiais.

Segundo Lacerda (2009), em alguns setores é notável o desempenho da logística reversa a exemplo da indústria de latas de alumínio, que desenvolveu meios inovadores na coleta de latas descartadas e reciclagem para gerar matéria prima. Entretanto, na indústria de eletrônicos, varejos e automóveis o gerenciamento da logística reversa ainda é recente.

A logística reversa sempre agregará valor de alguma natureza às empresas, seja através do retorno de bens ao ciclo de negócios ou ao ciclo produtivo. Todavia, o objetivo economico não é o único a ser alcançado pela logística reversa, fatores como a busca por competitividade e por um menor impacto ambiental são incentivos as empresas para adotá-la (MAGALHÃES; PIASSI; AGUIAR, 2011).

\section{Metodologia}

Trata-se de uma pesquisa quantitativa de natureza exploratória e descritiva. Desenvolvida a partir da elaboração de um questionário para o setor produtivo de eletroeletrônico. A survey foi aplicada à 252 empresas produtoras de eletroeletrônicos, cadastradas na Associação Brasileira da Indústria Eletro Eletrônica - ABINEE .

Também foram usados dados secundários obtidos em pesquisa bibliográfica, utilização de livros, artigos e revistas, e em casos estudados publicados por Jabbour e Jabbour (2012), que buscou identificar uma evolução ambiental das empresas de eletroeletrônicos a partir da adoção de práticas de Green Supply Chain Management (GSCM) com foco nos quesitos de design e avaliação do ciclo de vida do produto e por Arenhardt, Battistella e Franchi (2012) que identificaram ações de eco-design na indústria produtiva de eletroeletrônicos.

Para a aplicação do survey foi usado o Google Drive, um software livre, disponível online que permite o envio por e-mail e recebe as respostas oferecendo uma interface fácil para pesquisador e pesquisado. Foram abordadas empresas produtoras de eletroeletrônicos, associadas da ABINEE e 
cujos dados, a exceção dos e-mails, estão disponíveis no site oficial da associação. A entidade divide as empresas por tipos de produtos, dessa forma, a fim de focar apenas os produtos eletroeletrônicos produzidos que chegam ao usuário final e geram resíduos eletroeletrônicos foram escolhidos três setores de atuação das empresas associadas: o setor de informática com 133 empresas, o setor de telecomunicações que abrange 72 empresas e o setor de componentes eletroeletrônicos com 47 empresas, perfazendo um total de 252 empresas de Equipamento Eletro e Eletrônico - EEE cujos produtos geram resíduos eletroeletrônicos.

Dessas 252 empresas 17 foram excluídas por se tratarem de empresas que apenas exportam e outras por terem sua estrutura produtiva fora do Brasil, perfazendo um montante de 235 empresas atuantes e com perfil para a pesquisa.

Para a survey foram usadas perguntas abertas e fechadas, e a fim de trabalhar tais variáveis qualitativas e adaptá-las para representar uma serie quantitativa foi utilizada uma escala do tipo Likert.

A escala para ser definida envolve estabelecer premissas de relação entre os atributos do objeto e sua representação simbólica, atribuindo rótulos numéricos definidos pelo pesquisador. Para concebê-la "o pesquisador deve considerar o referencial teórico relativo à mensuração de eventos qualitativos e as características de seu objeto de estudo". (PEREIRA 2004, p. 64)

Para a análise dos dados coletados pela escala de Likert foi utilizado cálculo da tabulação ponderada que considera o peso de importância de cada escala para alcançar a média, conforme tabela 1 (SAMARA; BARROS, 2007).

Tabela 1 - As escalas e seus pesos.

\begin{tabular}{|c|c|c|c|c|c|c|}
\hline Peso & $\operatorname{vi(-2)}$ & vi (-1) & vi $(0)$ & vi (1) & vi (2) & \\
\hline Escala & \begin{tabular}{|l} 
Discordo \\
Totalmente
\end{tabular} & \begin{tabular}{|l|} 
Discordo \\
Parcialmente
\end{tabular} & \begin{tabular}{|l|} 
Nem \\
concordo/ \\
Nem \\
discordo \\
\end{tabular} & \begin{tabular}{|l} 
Concordo \\
Parcialmente
\end{tabular} & $\begin{array}{l}\text { Concordo } \\
\text { Totalmente }\end{array}$ & \begin{tabular}{|l} 
Média \\
Pondera \\
da \\
\end{tabular} \\
\hline \multicolumn{7}{|c|}{ Usa embalagens recicláveis em seus procutos } \\
\hline $\begin{array}{l}\text { Total de } \\
\text { respostas (60) }\end{array}$ & fi (2) & fi (3) & fi (5) & fi $(18)$ & fi (32) & 1,3 \\
\hline
\end{tabular}

Fonte: Kobal (2013)

Nota: As médias de todas as questões são obtidas pelo quociente entre o somatório de frequência $\mathrm{x}$ peso e o total de respostas obtidas (SAMARA; BARROS 2007, p.177).

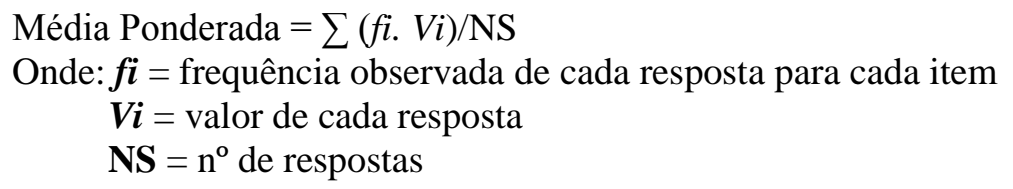

Os valores menores que 0 são considerados como discordantes e maiores que 0 , como concordantes. O valor exatamente 0 será considerado "indiferente" ou "sem opinião", sendo o "ponto neutro" (SAMARA; BARROS, 2007).

Antes da média ponderada foi calculado o Alfa de Cronbach. Freitas e Rodrigues (2005, p. 2) explicam que "o coeficiente $\alpha$ de Cronbach é uma das estimativas da confiabilidade de um questionário que tenha sido aplicado em uma pesquisa". Freitas e Rodrigues (2005) sugerem a classificação da confiabilidade a partir do cálculo do coeficiente $\alpha$ de Cronbach de acordo com os limites $0,60<\alpha \leq 0,75$ para confiabilidade alta e $0,75<\alpha \leq 0,90$ para confiabilidade muito alta.

Sendo assim, confirmou-se a confiabilidade dos grupos de perguntas sobre cadeia de suprimento e cadeia de suprimento verde com valores de $\alpha>80 \%$, e no grupo de perguntas sobre logística reversa e parceria com o setor de resíduos eletroeletrônicos com valores de $\alpha>60 \%$.

\section{Análise e Discussão dos Resultados}

\subsection{O perfil das empresas produtoras de eletroeletrônico.}

Conforme explanado anteriormente a indústria brasileira de eletroeletrônico reúne cerca de 4.000 empresas, sendo $80 \%$ delas de pequeno porte com menos de 100 colaboradores. Trata-se de um 
setor de capital intensivo que gera cerca de 180 mil empregos diretos, tendo atingido em 2011 um faturamento de 80 bilhões de dólares, representando cerca de 3,5\% do PIB brasileiro. (ABINEE, 2012)

$\mathrm{O}$ total de empresas respondentes foi 60 oriundas de 8 diferentes estados brasileiros: Amazonas (1), Ceará (2), Pernambuco (1), Minas Gerais (6), São Paulo (34), Paraná (5), Santa Catarina (1) e Rio Grande do Sul (10).

Percebe-se uma maior concentração de empresas do setor produtivo de eletroeletrônicos no sul do país, com 55,7\% delas no estado de São Paulo e 16,4\% no Rio Grande do Sul e menos de 10\% nos outros seis estados. O fato de estados como Paraná e Santa Catarina terem leis próprias para resíduos eletroeletrônicos, parece não ter influenciado a participação das empresas na pesquisa, visto o baixo número de empresas respondentes nesses estados, diferente de São Paulo cuja lei também vigora e o interesse foi marcante.

Do total das empresas respondentes, 42,6\% são consideradas médio porte, $27,9 \%$ grande, $24,6 \%$ pequeno porte e apenas $3,3 \%$ microempresa. O fato de $67,2 \%$ das empresas produtivas serem empresas de pequeno e médio porte, talvez explique a dificuldade de se criar um sistema de logística reversa e reciclagem sistemática na cadeia envolvendo os eletroeletrônicos - indústria, comerciantes e consumidores.

Esta realidade talvez possa também explicar a resistência dos fabricantes brasileiros em assumir a gestão dos resíduos eletroeletrônicos de seus produtos no final de vida útil, conforme afirma Bizzo, (2007).

\subsection{A cadeia de suprimento das empresas produtivas.}

Todas as questões abordadas sobre esse grupo de perguntas - cadeia de suprimento - geraram resultados de concordância, evidenciando a existência de um relacionamento nos elos da cadeia de suprimento da indústria eletroeletrônica. A tabela 2 traz as médias ponderadas dos atributos da cadeia de suprimento do setor produtivo.

Tabela 2-Média dos atributos da cadeia de suprimento.

\begin{tabular}{l|r}
\hline \multicolumn{1}{c|}{ RESULTADO CADEIA DE SUPRIMENTO } & \multicolumn{1}{l}{$\begin{array}{l}\text { Média } \\
\text { Ponderada }\end{array}$} \\
\hline Área especifica suprimento & 1,08 \\
\hline Redução custos entre parceiros & 1,38 \\
\hline Há troca bens/inf com fornecedores & 0,90 \\
\hline Há troca bens/inf com distribuidores & 0,63 \\
\hline Integração com fornecedores & 0,97 \\
\hline Visão de longo prazo com fornecedor & 1,0 \\
\hline Há troca bens/inf com varejistas & 0,08 \\
\hline Trocainform custos & 0,73 \\
\hline Há area de logistica & 1,13 \\
\hline Logistica integrada com cadeia de suprimento & 0,95 \\
\hline
\end{tabular}

Fonte: Os autores (2013)

Diante dos resultados obtidos percebe-se que a gestão da cadeia de suprimento é uma ferramenta desenvolvida pelo setor produtivo. A gestão abrange área de suprimento, área de logística e uma integração entre ambas com médias de $(1,08),(1,13)$ e $(0,95)$ respectivamente.

Há também uma integração com os fornecedores $(0,97)$, uma parceria em longo prazo ainda maior com os mesmos (1), gerando uma troca de informações de custos entre fornecedores e distribuidores $(0,73)$.

Toda essa complexidade de situações existentes ao longo da cadeia bem, como o tipo de gerenciamento e a extensão é que de acordo com Neutzling (2012) determinará a gestão da cadeia de suprimento, e será a busca por melhoria nesses processos que gerará vantagens competitivas.

O atributo redução dos custos entre os parceiros teve a média mais expressiva $(1,38)$ entre todas, e pode estar sendo estimulado através da troca de informações entre os fornecedores $(0,90)$ e entre os distribuidores $(0,63)$ sendo estes os responsáveis pelo abastecimento dos varejistas e o elo 
direto com eles, e os varejistas responsáveis pelo atendimento aos clientes finais, o que talvez explique o menor índice evidenciado de troca de informações entre empresas e varejistas $(0,08)$. Esse resultado expressivo na média dos custos confirma Corrêa (2010) que aborda a importância da troca de informações entre empresa e distribuidor, a fim de diminuir os custos operacionais.

Diante dos elos identificados e da união dos mesmos, pode-se considerar a cadeia do setor produtivo de eletroeletrônico como uma cadeia de suprimento one-way, definida por Corrêa (2010) e Beamon (1999) como uma cadeia com processo de produção integrada em que as matérias-primas são convertidas em produtos finais, e em seguida, entregues aos clientes.

\subsection{Características de cadeia de suprimento verde nas empresas produtivas.}

A cadeia de suprimento verde traz em seus principios forte preocupação ambiental, uma nova postura em relação aos produtos consumidos e aos processos de fabricação tornando imperativo analisar os efeitos do ciclo dos produtos e dos processos, visando um menor impacto ambiental (BEAMON,1999; SARKIS, 2003; AN et. al., 2008; BARBIERI; CAJAZEIRA; BRANCHINI, 2009; SCHROEDER; GOLDSTEIN; RUNGTUSANATHAM, 2011).

As perguntas sobre ações verdes tiveram como suporte o modelo de Srivastava (2007, p.55) para identificar características de cadeia de suprimento verde e ações verdes, focou-se os estudos de Design Verde com a abordagem do Ciclo de Vida de Produto, e dentro de Operações Verdes foi explorado apenas a Gestão de Resíduos e a Logística Reversa.

Algumas práticas utilizadas por Jabbour e Jabbour (2012) em um de seus trabalhos também com o setor produtivo de eletroeletrônico brasileiro foram replicados neste estudo, a exemplo dos itens sobre implantação da ISO14001, práticas ambientais para seleção de fornecedores, projetos de produtos visando, redução, reuso, reciclagem ou recuperação de materiais, componentes ou energia e projeto de produto para evitar ou reduzir o uso de produtos perigosos e tóxicos.

Nesta pesquisa não foram confirmados o quesito ISO14001 implantada e nem fornecedores com práticas ambientais como pré-requisito para seleção, evidenciados no trabalho de Jabbour e Jabbour (2012). Os demais resultados conforme tabela 3 confirmam características de ações verdes na cadeia de suprimento do eletroeletrônico brasileiro assim como Jabbour e Jabbour (2012).

Tabela 3- Identificando as Ações Verdes na cadeia de suprimento.

\begin{tabular}{l|r}
\hline RESULTADO DA CADEIA DE SUPRIMENTO VERDE & $\begin{array}{c}\text { Média } \\
\text { Ponderada }\end{array}$ \\
\hline ISO 14001 implantada & $-1,03$ \\
\hline Envolvimentos de equipes planejamento & 1,18 \\
\hline Minimiz. entre parceiros de gases efeito estufa e recursos & 0,6 \\
\hline Pre requisito de fornecedor: desenvolva ações ambientais & $-0,1$ \\
\hline Usa materias primas menos poluentes & 1,10 \\
\hline Mp legal de fornecedores & 1,22 \\
\hline $\begin{array}{l}\text { Design dos seus produtos visa a facilidade de } \\
\text { desmonte/reciclagem }\end{array}$ & 0,72 \\
\hline Design dos seus produtos visa a durabilidade & 1,58 \\
\hline $\begin{array}{l}\text { Design dos seus produtos visa a capacidade de reparação } \\
\text { (conserto) }\end{array}$ & 1,35 \\
\hline Usa embalagens recicláveis em seus produtos & 1,25 \\
\hline $\begin{array}{l}\text { Otimizar o tipo e a quantidade de materiais usados no processo } \\
\text { produtivo }\end{array}$ & 1,57 \\
\hline Avaliação do ciclo de vida de seus produtos. & 0,57 \\
\hline Canal de comun.com o cliente retorno de produto & 0,02 \\
\hline Controla os impactos de emissões atmosféricas significativas. & 0,52 \\
\hline
\end{tabular}

Fonte: Os autores (2013) 
O uso de ISO 14001 pelas empresas gerou uma média de (-1,03), evidenciando a não utilização da ferramenta pelas empresas da pesquisa. O baixo resultado pode ser explicado pelo pequeno número de empresas de grande porte na amostra apenas 17 , ou seja, $27,9 \%$ do total. Pela complexidade da norma, abrangência e controle não é comum encontrar a mesma implantada em pequenas e médias empresas, grande maioria de respondentes.

Empresas que possuam ISO14001 têm seus processos e normas auditadas voltadas para a melhoria do desempenho ambiental e a redução no uso dos recursos naturais, além do ACV dos produtos que abrange o monitoramento de todos esses recursos. Essa ferramenta (ACV) possui metodologia de manufatura e auxilia a busca por resultados efetivos de melhoria na eficiência do uso de recursos e na prevenção da poluição, medindo o consumo de energia, a manufatura, o transporte, as compras e permite gerar declarações de rótulos ambientais e indicadores ambientais (MAGALHÃES, 2010; PIGOSSO et.al., 2010; BARBIERI; CAJAZEIRA, 2009; BARBIERI, 2007; SARKIS, 2003).

A escolha de fornecedores com ações ambientais como pré-requisito não foi evidenciado ($0,1)$ tal resultado pode ser explicado também pelo não uso da ISO14001 visto que empresas com essa certificação é que costumam exigir esse perfil como pré- requisito na escolha do seu fornecedor.

Foi identificada a preocupação com materiais menos poluentes $(1,10)$ assim como no trabalho de Jabbour e Jabbour (2012), e com matéria prima de origem legal $(1,22)$.

As ações que visam minimizar entre os parceiros e controlar o impacto ambiental gerado pela indústria no quesito água, energia, gases de efeito estufa, foram evidenciadas timidamente $(0,6)$ e $(0,52)$ respectivamente.

Tal resultado também se refletiu no compromisso das empresas com a Avaliação do Ciclo de Vida dos produtos $(0,57)$, ou seja, embora seja importante e tenha sido criado para ajudar a indústria a mensurar melhor o consumo de seus recursos e otimizá-los minimizando os impactos ambientais e servindo de base à identificação de oportunidades para a melhoria do desempenho ambiental em diversos pontos do ciclo de vida de seus produtos, o setor produtivo do eletroeletrônico brasileiro ainda não aplica eficientemente a ferramenta.

Sobre os projetos de produtos e a preocupação com o design identificou-se o uso do design voltado para durabilidade e reparação com média de $(1,58)$, e a preocupação das empresas também com o design visando a capacidade de reparação (conserto) $(1,35)$ e embora seja considerado menos importante que os anteriores pelas empresas, elas também pensam no design visando o desmonte/reciclagem alcançando uma média de $(0,72)$ resultado que evidencia preocupação da indústria eletroeletrônica pelo design de seus processos e produtos entretanto, a menor média alcançada no design voltado para o desmonte/reciclagem refletindo os resultados do trabalho de Arenhardt, Battistella e Franchi (2012) onde o que estimula a indústria por melhoria no design de seus processos e produtos é a redução de custos e o aumento de competitividade e não o apelo ambiental.

Ações de design verde no setor produtivo de eletroeletrônico também foi verificado no uso de embalagens recicláveis em seus produtos e na otimização do tipo e quantidade de materiais usados no processo produtivo com médias de $(1,25)$ e $(1,57)$ respectivamente, demonstrando uma evidente preocupação da indústria com o processo produtivo.

Todo esse resultado nos itens relativos ao design verde pode ser consequência de envolvimento da equipe de planejamento que teve como média ponderada $(1,18)$.

Tais resultados confirmam também o modelo de Institut Für Konstruktionswissens (1996), Schroeder, Goldstein e Rungtusanatham (2011) e a pesquisa de Arenhardt, Battistella e Franchi (2012) que encontraram características de uma gestão da cadeia de suprimento verde, em especial no quesito design verde ou eco-design a partir dos construtos inovação de produtos verdes e inovação de processos verdes no setor de eletroeletrônico brasileiro.

O uso de embalagens recicláveis pelas empresas $(1,25)$ foi confirmado ao evidenciarmos que $67 \%$ das empresas possuem mais de $75 \%$ de seus produtos com embalagens recicláveis. Verificou-se também que ao se considerar o acumulado de empresas com embalagens recicláveis acima de $51 \%$ tem-se que $84 \%$ das empresas do setor possui algum tipo de embalagem reciclável. Percebe-se uma tendência na escolha de embalagens reutilizáveis, confirmando Liva, Pontelo e Oliveira (2003) que dão ênfase a importância de embalagens recicláveis com o intuito de reduzir o custo final do produto além do impacto negativo ao meio ambiente. 
Sobre a porcentagem dos produtos que são recicláveis identificou-se que $57 \%$ das empresas possuem em seu portfólio mais de $51 \%$ de produtos passíveis de reciclagem. Enquanto isso, apenas $8 \%$ não dispõe de nenhum tipo de produto reciclável.

Mesmo possuindo produtos recicláveis e considerando este produto no final de sua vida útil, quando avaliado a gestão de resíduos evidenciou-se que apenas 0,02 das empresas possuem um canal de comunicação com o cliente para o retorno dos seus produtos. Importante frisar que esse canal de comunicação é para todos os tipos de produtos retornáveis o que inclui os defeituosos e os fora de linha.

Quando se analisa os resultados sobre as fontes alternativas de energia percebe-se que o perfil do setor de eletroeletrônico carece de fontes alternativas, $65 \%$ das empresas pesquisadas não possuem nenhuma fonte alternativa e as que utilizam 36 a $50 \%$ de energia alternativa não ultrapassa $3 \%$.

Ações de reaproveitamento de água não são evidentes no setor produtivo de eletroeletrônico, somam $48 \%$ o total de empresas que não reaproveitam nenhuma porcentagem de água utilizada, nem no processo produtivo nem no sistema normal do uso da água.

Não se pode considerar a existência de uma cadeia de suprimento verde no setor de eletroeletrônicos brasileiro, entretanto os resultados apontam o despertamento dessa indústria com a sustentabilidade ambiental através de várias ações com características verdes. Algumas evidenciadas com médias consideráveis como a otimização do processo produtivo, o uso do design voltado para a durabilidade e conserto e o uso de embalagens recicláveis.

Entretanto, mesmo com todas essas ações a visão de Bizzo (2007) de que há poucos exemplos de articulação voluntária do setor produtivo para recuperação ou reciclagem desses insumos e ainda é incipiente a utilização de eco-design e inovação na concepção dos produtos é verdadeira, pois o design visando a facilidade de desmonte e de reciclagem e a preocupação com a avaliação do ciclo de vida de produtos embora tenham sido evidenciados foi incipiente em comparação com a preocupação da indústria com o design visando a durabilidade e o conserto, o que demonstra a pouca parceria com o setor de resíduos eletroeletrônicos e a baixa aplicação do Programa Brasileiro de Avaliação do Ciclo de Vida- PBACV. 


\subsection{A logística reversa e a parceria com o setor de resíduos eletroeletrônicos}

Conforme tabela 4 percebe-se que o média ponderada não evidenciou a preocupação do setor produtivo de eletroeletrônico pelo desmonte/reciclagem de seus produtos $(-0,07)$, nem tão pouco os produtos vencidos/fora de linha $(-0,8)$.

Embora com baixa evidenciação os produtos defeituosos voltam para a linha de produção $(0,02)$. E considerando a média ponderada das respostas para a preocupação do setor com a produção de gases poluentes na logística reversa, o resultado foi neutro (0).

Os resultados mostraram que as empresas produtivas do setor possuem parceria com o setor de resíduos, entretanto, este resultado foi timidamente evidenciado com média de apenas 0,35 e o número de respostas afirmativas encontradas não condiz com o número de empresas que efetivamente coletam seus produtos pós-consumo. Percebe-se um viés nas respostas das empresas, pois são apenas 23 (38\%) as empresas que fazem a logística reversa de seus produtos pós-consumo e são 38 (63\%) as empresas que afirmam manter parceria na entrega de seus produtos pós-consumo junto ao setor de resíduos eletroeletrônicos.

Cabe aqui um aprofundamento em pesquisas futuras a fim de explicar o viés encontrado nessa parceria e o porquê de tão baixa evidenciação na parceria do setor produtivo de eletroeletrônico com o setor de resíduos.

Identificou-se a existência de uma estrutura de logística reversa desenvolvida pelas empresas para $63 \%$ das respondentes. Algumas empresas desenvolvem mais de um tipo de logística reversa, $35 \%$ delas usam empresa terceirizada, $22 \%$ parcerias com lojas credenciadas, $2 \%$ terceirizados com obtenção de crédito e $15 \%$ possuem produtos não passível de rastreamento.

Tabela 4 - Identificando a logística reversa da indústria e a relação com o setor de resíduos.

\begin{tabular}{|c|c|}
\hline RESULTADO LR E SETOR DE RESIDUOS & $\begin{array}{c}\text { Média } \\
\text { Ponderada } \\
\end{array}$ \\
\hline Produtos defeituosos voltam para a linha de produção. & 0,02 \\
\hline Produtos vencidos/fora de linha voltam para a linha de produçáo & $-0,9$ \\
\hline Desenvolve processo de desmonte ou reciclagem & $-0,0,07$ \\
\hline $\begin{array}{l}\text { Possui parceria com as empresas de residuos } \\
\text { eletroeletrônicos. }\end{array}$ & 0,35 \\
\hline Considera a produçâo de gases poluentes na logistica & 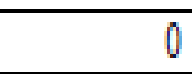 \\
\hline Tem conhecimento da pars- nivel estratégico & 0,17 \\
\hline Tem conhecimento da pars- nivel operacional & 0,02 \\
\hline A expresăo lixo eletơnico cinza é conhecida & $-0,02$ \\
\hline
\end{tabular}

Fonte: Os autores (2013)

Quanto aos tipos de produtos coletados pela logística reversa desenvolvida pelas empresas, ficou demonstrado que $83 \%$ das empresas fazem a coleta de seus produtos defeituosos, $32 \%$ coletam os que saíram de linha e apenas $38 \%$ fazem a logística reversa de seus produtos pós-consumo, enquanto $28 \%$ das empresas afirmam possuir produto não passível de rastreabilidade.

Evidenciou-se que $37 \%$ das empresas não possuem parceria com as empresas de resíduos eletroeletrônicos e apenas $23 \%$ delas entregam mais de $50 \%$ de seus resíduos ao setor. Tal resultado corrobora a tímida parceria evidenciada pela média ponderada entre setor produtivo e setor de resíduos $(0,35)$, demonstrando que o desempenho da logística reversa nesse setor ainda carece de estímulos confirmando Sarkis (2003), Donato (2008) e Lacerda (2009) que afirmam que entre as funções operacionais, a logística reversa é a menos desenvolvida e estudada dentre todas, e na indústria de eletrônicos, varejos e automóveis o gerenciamento da logística reversa ainda é recente. Também 
confirma Bizzo (2007) quando afirma que há uma resistência da indústria em assumir a gestão dos resíduos eletroeletrônicos de seus produtos no final de sua vida.

Na parceria entre setor produtivo e setor de resíduos eletroeletrônicos, as empresas (52\%) não mantém uma periodicidade de entrega dos produtos.

A logística reversa evidenciada no setor produtivo de eletroeletrônico é a do canal reverso do reuso - produtos consertados e recuperados com o propósito de recapturar valor ou descarte apropriado, não se evidenciando um canal reverso de reciclagem - quando o produto dá origem a novas matérias primas, nem de desmanche - produtos que sofrem descaracterização ( LEITE, 2009; ROGERS; TIBBEN-LEMBKE, 1998, NHAN; SOUZA; AGUIAR, 2003; DONATO, 2008).

Alguns países da União Européia conseguiram otimizar seu processo de coleta e descaracterização dos resíduos eletroeletrônicos através de um método baseado nas características contidas nos resíduos, que considera e quantifica os resíduos valiosos, os perigosos, os processos de tecnologia de recuperação e a reutilização. Essas e outras considerações foram instituídas através da Lei WEEE-diretiva de 2003 da União Européia visando um melhor desempenho da logística reversa desses resíduos nesses países (CHANCEREL; ROTTER, 2009).

Caso essa realidade fosse seguida também pelo Brasil com reciclagem orientada a caracterização dos resíduos, além de unidades de processamento com pontos de coleta e estações de tratamento, o envolvimento do setor produtivo com o setor de resíduos eletroeletronico seria melhor evidenciado.

Sobre a expressão lixo eletrônico cinza apesar da ABINEE (2011) abordar o problema do mercado cinza (produtos ilegais, piratas) de eletroeletrônicos, e considerar esse o maior desafio da lei de resíduos sólidos, tal preocupação não é compartilhada pelas empresas pesquisadas, pois não se evidenciou o conhecimento da expressão lixo eletrônico cinza pelas empresas que obteve média ponderada de $-0,02$. Apenas cinco grandes empresas, duas médias e uma pequena confirmaram o conhecimento de tal expressão nas suas respostas, a maioria não sabe do que se trata, pensa que é o resíduo da produção ou desconhece a expressão.

Os resultados da pesquisa também evidenciaram que as empresas carecem de um maior domínio da lei, dos seus direitos e deveres como indústria produtora. Pois se evidenciou um baixo conhecimento do uso da lei 12.305/2010 da PNRS quanto às oportunidades, deveres e como realizar as obrigações e obter benefícios tanto a nível operacional $(0,02)$ como a nível estratégico $(0,17)$, corroborando com Monteiro (2012) que afirma que o desafio da Lei está na concepção e na implementação de modelos de gestão que visem resultados dinâmicos, abrangentes e multidimensionais.

\section{Considerações Finais}

O objetivo geral da pesquisa foi analisar de que forma a indústria produtiva de eletroeletrônico têm atuado na cadeia e na logística reversa desses resíduos.

O primeiro objetivo específico foi verificar as características da cadeia de suprimento da indústria eletroeletrônica e a parceria com o setor de resíduos eletroeletrônicos. A partir dele não foi confirmado o primeiro pressuposto a de que a cadeia produtiva do eletroeletrônico não é parceira do setor de resíduos eletroeletrônicos.

Embora tenha sido evidenciada uma parceria entre o setor produtivo e o setor de resíduos eletroeletrônicos e se perceba uma preocupação da indústria com seus produtos pós-consumo, esse elo entre os setores é tímido e pouco evidente.

Entretanto, as empresas que entregam seus produtos ao setor de resíduos não o fazem com periodicidade e o número delas que fazem a coleta de seus produtos pós-consumo é bem menor que o número de empresas que afirmam possuírem parceria com o setor de resíduos eletroeletrônicos, viés encontrado que confirma o tímido resultado da parceria e estimula a novas pesquisas.

Identificou-se também uma relação entre os parceiros na cadeia produtiva de eletroeletrônico (fornecedores, distribuidores, varejistas), uma busca nessa parceria por menores custos, além de uma visão a longo prazo no relacionamento com fornecedores. Também se evidenciou áreas de logísticas e suprimento na indústria.

Em relação ao segundo objetivo específico, identificaram-se ações verdes do setor produtivo do eletroeletrônico na perspectiva do design verde, da avaliação do ciclo de vida e da logística reversa, 
confirmando assim o segundo pressuposto o de que o setor produtivo de eletroeletrônico desenvolve a avaliação do ciclo de vida do produto, aplica eco-design na elaboração dos mesmos e mantém uma logística reversa possuindo características de cadeia de suprimento verde.

O setor produtivo de eletroeletrônico possui algumas características da cadeia de suprimento verde e tais ações foram evidenciadas também no uso de matéria prima menos poluente, no relacionamento com fornecedores, no uso de embalagens recicláveis em seus produtos, na otimização do processo produtivo e principalmente na busca de projetos com design visando a durabilidade e capacidade de reparação e a implantação da logística reversa inclusive de produtos pós-consumo. São resultados positivos que sinalizam uma preocupação da indústria com seus produtos, e sua contribuição com a sustentabilidade ambiental.

$\mathrm{O}$ uso da ferramenta de avaliação do ciclo de vida do produto também foi evidenciado, mas considerando sua importância e seu apelo ambiental se faz necessário um maior comprometimento da indústria nesse quesito.

Não foi evidenciada a implantação da ferramenta ISO14001 nem a preocupação com o desempenho ambiental dos fornecedores como pré-requisito para a seleção dos mesmos, nem tão pouco se comprovou o controle com a produção de gases poluentes na logística, único item que gerou um resultado neutro, resultados que demonstram que o empenho em melhorias ambientais tem sido pontual e não chegou ainda aos elos da cadeia.

A fim de fortalecer e ampliar as parcerias entre estes dois setores, aumentando principalmente a demanda por matéria prima e os benefícios sociais e ambientais que essa parceria pode trazer é necessário que haja incentivos visando o aumento de empresas coletoras e recicladoras. Incentivos também para a indústria produtiva de eletroeletrônico de forma a estimulá-la na busca por produtos mais sustentáveis, nas ações de logística reversa ampliando a parceria com o setor de resíduos, aumentando a oferta de matéria prima para este setor e desenvolvendo uma cadeia reversa fortalecida e ambientalmente correta.

Cabe ainda à industria produtiva a responsabilidade de produzir produtos mais duráveis, desmontáveis e recicláveis. É preciso também que ela desenvolva um interesse genuíno nos seus produtos pós-uso, a ponto de estruturar um canal de recebimento de seus produtos e estender tal atitude aos seus distribuidores, vendedores e lojistas, buscando parceria com toda a cadeia logística e com o setor de resíduo eletroeletrônico a fim de otimizar as ações de descarte.

A pesquisa revelou a necessidade de desenvolver uma cadeia de logística reversa estruturada, onde todos os envolvidos - governos federais, estaduais, municipais, indústria, setor de resíduos, de reciclagem e população, estejam diretamente envolvidos com o problema e tenham o seu quinhão de responsabilidade para que os resíduos eletroeletrônicos venham a ter seu descarte correto e a nação brasileira não venha a enfrentar graves problemas ambientais e de saúde devido a eles.

No Brasil embora haja legislação sobre a Avaliação do Ciclo de Vida de Produto, sobre a responsabilidade compartilhada entre produtor, distribuidor, consumidor e outros envolvidos, não foi definido ainda como fiscalizar, cobrar e punir.

Algumas questões foram consideradas pelos autores como limitações no desenvolvimento da pesquisa: (i) o pequeno número de estudos acadêmicos sobre o setor de resíduos eletroeletrônicos brasileiro, (ii) o baixo número de empresas legais desse setor no país, (iii) o fato da grande maioria delas estarem localizadas no sul e sudeste do Brasil, e (iv) a resistência do setor produtivo de eletroeletrônico em participar da pesquisa, principalmente as multinacionais, muito embora tenham um forte marketing ambiental a grande maioria negou-se a responder o questionário.

Os autores sugerem para futuras pesquisas a ampliação da amostra desta pesquisa, agregar outros estudos de modelo de países que possuam uma estrutura efetiva de coleta e reciclagem de resíduos eletroeletrônicos e como eles superaram as dificuldades como as identificadas no setor brasileiro.

\section{Referências}

ABINEE. Associação Brasileira da Indústria Elétrica e Eletrônica Panorama Econômico 2011 e Desempenho Setorial. 2011. Disponível em: <http://www.abinee.org.br/informac/arquivos/pan2011.pdf>. Acesso em: 20 mar. 2012. 
. A indústria elétrica e eletrônica impulsionando a economia verde e a sustentabilidade. 2012. Disponível em: 〈http://www.abinee.org.br/programas/imagens/abinee20.pdf >. Acesso em: 18 out. 2012.

Desempenho setorial - perspectiva para 2013. 2013. Disponível em:

<http://www.abinee.org.br/abinee/decon/decon15.htm\#perspec.> Acesso em: 23 mar. 2013.

AN, Hee Kyung; AMANO; Teruyoshi; UTSUMI ,Hideki; MATSUI, Saburo. A framework for Green Supply Chain Management complying with RoHS directive. In: CRRConference 2008. Queen's University Belfast. Set, 2008.

ARENHARDT, D. L.; BATTISTELLA, L. F.; FRANCHI, T. S. A influência da inovação verde na busca de vantagem competitiva das empresas dos setores elétrico e eletrônico brasileiro. In:

ENCONTRO DA ASSOCIAÇÃO NACIONAL DE PÓS GRADUAÇÃO E PESQUISA EM

ADMINISTRAÇÃO- ENANPAD, 2012. Anais... Rio de Janeiro: ENANPAD, Rio de Janeiro, 2012. CD ROM.

BARBIERI, J.C.; CAZAJEIRA, J. E. R. Avaliação do ciclo de vida do produto como instrumento de gestão da cadeia de suprimento - o caso do papel reciclado. In: SIMPÓSIO DE ADMINISTRAÇÃO DA PRODUÇÃO, LOGÍSTICA E OPERAÇÕES INTERNACIONAIS, 2009. Anais ... São Paulo: FGV- EAESP, 2009. CD-ROM

BARBIERI, J.C. Gestão ambiental empresarial: conceitos, modelos e instrumentos. 2 ed. Ed. Saraiva. São Paulo. 2007

BARBIERI, J.C.; CAZAJEIRA, J. E. R.; BRANCHINI, O. Cadeia de Suprimento e avaliação do ciclo de vida do produto: revisão teórica e exemplo de aplicação. Revista o Papel, 2009. Disponível em: <http://www.revistaopapel.org.br/noticiaanexos/1311883092 de7b3647b9dfc4ef6d0a128a5cb3ec6b 1778858231.pdf>. Acesso em $21 \mathrm{dez}$ 2011.

BEAMON, Benita M. Designing the Green Supply Chain. Logistics Information Management. v. 12, n. 4, p. 332-342. 1999

BIZZO, W.A. Gestão de resíduos e gestão ambiental da indústria eletroeletrônica. [ABINEE Tec 2007], 2007. Slides. Disponível em: 〈http://www.tec.abinee.org.br2007arquivoss702.pdf>. Acesso em 24 maio 2012.

CHANCEREL, P; ROTTER, S. Recycling-oriented characterization of small waste electrical and electronic equipment. Waste Management , n. 29, p. 2336-2352, 2009.

CORRÊA, L. H. Gestão de redes de suprimento: integrando cadeias de suprimento no mundo globalizado. São Paulo: Atlas, 2010.

DONATO, Vitório. Logística Verde - uma abordagem sócio-ambiental. Rio de Janeiro: Editora Ciência Moderna Ltda, 2008

FREITAS, A. L. P; RODRIGUES, S.G. A avaliação da confiabilidade de questionários: uma análise utilizando o coeficiente alfa de Cronbach. In: XII SIMPÓSIO DE ENGENHARIA DE PRODUÇÃOSIMPEP, 2005. Anais...Bauru - São Paulo, 2005. Disponível em:< http://www.simpep.feb.unesp.br/anais_simpep_aux.php?e=12>. Acesso em 05 jan. 2013.

INSTITUT FÜR KONSTRUKTIONSWISSENS. Eco-design on line Pilot. Software on line de Ecodesign criado em 1996. Disponível em: 〈http://www.ecodesign.at/pilot〉. Acesso em: 3 jul. 2012

JABBOUR, A. B.L.S.; JABBOUR, C.J. C. Evolução da gestão ambiental e a adoção de práticas de Green Supply Chain Management no setor eletroeletrônico brasileiro. In: ENCONTRO DA ASSOCIAÇÃO NACIONAL DE PÓS GRADUAÇÃO E PESQUISA EM ADMINISTRAÇÃO- ENANPAD, 2012. Anais... Rio de Janeiro: ENANPAD, Rio de Janeiro, 2012. CD ROM 
KARLSSON, R.; LUTTROPP, C. EcoDesign: what's happening? An overview of the subject area of EcoDesign and of the papers in this special issue. Journal of Cleaner Production, n. 14, p. 12911298, 2006.

KOBAL, A.B.C.; SANTOS, S.M; SOARES, F.A; LÁZARO, J.C. Cadeia de suprimento verde e logística reversa - os desafios com os resíduos eletroeletrônicos. Revista Produto \& Produção. v.14, n.1, p.55-83, fev.2013. Disponível em:

<hhttp://seer.ufrgs.br/ProdutoProducao/article/view/29594/24772>. Acesso em 4 março 2013.

KOBAL, A.B.C. Cadeia de suprimento e cadeia reversa: um estudo do setor de resíduos eletroeletrônico. 2013.185 f. Dissertação. (Mestrado Acadêmico em Administração e Controladoria). Universidade Federal do Ceará, Faculdade de Economia, Administração, Atuária, Contabilidade e Secretariado Executivo. Disponível em: $<$ http://www.si3.ufc.br/sigaa/stricto/banca_pos/consulta_defesas.jsf.>.

LACERDA, Leonardo. Logística Reversa: uma visão sobre os conceitos básicos e as práticas operacionais. 2009. Disponível em:

<http://www.sargas.com.br/site/artigos_pdf/artigo_logistica_reversa_leonardo_lacerda.pdf.> Acesso em 23 dez 2011.

LEITE, P.R. Logística reversa - meio ambiente e competitividade. 2. ed. São Paulo: Pearson Prentice Hall, 2009.

LEITE, P.R.; LAVEZ, N.; SOUZA, V.M. Fatores da logística reversa que influem no reaproveitamento do "lixo eletrônico"-um estudo no setor de informática. In: SIMPÓSIO DE ADMINISTRAÇÃO DA PRODUÇÃO, LOGÍSTICA E OPERAÇÕES INTERNACIONAIS-SIMPOI, 2009. Anais... São Paulo: FGV- EAESP, 2009. CD-ROM

LIVA, P. B. G.; PONTELO, V.S. L.; OLIVEIRA, W. S. Logística reversa. Techoje - uma revista de opinião, 2003. Disponível em: http://www.ietec.com.br/site/techoje/categoria/detalhe artigo/301. Acesso em 22 dez 2011.

MAGALHÃES, A. C. B. O espaço dos resíduos sólidos domiciliares e de sua logística reversa na geografia urbana: Diagnóstico e modelo de gestão pró-ativo. 2010. 171 f. Dissertação (Mestrado em Geografia)- Programa de Pós-Graduação em Geografia, da Universidade Federal de Uberlândia, 2010.

MAGALHÃES, A.P. S; PIASSI, L.M; AGUIAR, E.M. Logística reversa de eletrodomésticos da linha branca: processo de escolha pelo método de análise hierárquica (AHP). In: SIMPÓSIO DE ADMINISTRAÇÃO DA PRODUÇÃO, LOGÍSTICA E OPERAÇÕES INTERNACIONAISSIMPOI, 2011. Anais... São Paulo: FGV - EAESP, 2011. Disponível em: 〈http://www.simpoi.fgvsp.br/arquivo/2011/artigos/E2011 T00409 PCN42096.pdf >. Acesso em 26 set. 2012.

MINISTÉRIO DO DESENVOLVIMENTO, INDÚSTRIA E COMÉRCIO EXTERIOR- MDIC. MDIC e ABDI divulgam estudo sobre logística reversa de eletroeletrônicos. 2014. Disponível em: 〈http://www.mdic.gov.br/sitio/interna/noticia.php?area=2\&noticia=13019>. Acesso em 2 fev. 2014.

MONTEIRO, J.C. A política nacional de resíduos sólidos e as áreas da logística - parte 1. Administradores.com 2012. Disponível em: 〈http://www.administradores.com.br/informese/artigos/a-politica-nacional-de-residuos-solidos-e-as-areas-da-logistica-parte-1/63265/>. Acesso em 7 set. 2012.

MOREIRA, Assis. ONU alerta para aumento do lixo eletrônico em emergentes. Globo Economia 23 fev. 2010. Disponível em: 〈http://oglobo.globo.com/economia/onu-alerta-para-aumento-do-lixoeletronico-em-emergentes-3049634>. Acesso em $20 \mathrm{dez} 2011$.

NHAN, A. N. N. P.; SOUZA, C. G.; AGUIAR, R. A. A. Logística reversa no Brasil: a visão dos especialistas. In: ENCONTRO NAC. DE ENG. DE PRODUÇÃO- ENEGEP, 2003. Anais ... Ouro Preto, Minas Gerais: ABEPRO 2003. CD-ROM 
NEUTZLING, D.M.. Criação de vantagens competitivas por meio da gestão sustentável de cadeias de suprimentos. 2012.100f. Projeto de tese (Doutorado em Administração)- Universidade Federal do Rio Grande do Sul. Rio Grande do Sul, 2012.

PEREIRA, J.C.R. Análise de dados qualitativos- estratégias metodológicas para as ciências da saúde, humanas e sociais. 3 ed. 1 reimpr. São Paulo: Ed. da Universidade de São Paulo, 2004.

PIGOSSO, D. C.A.; ZANETTE, E. T.; GUELERE, A. F.; OMETTO, A. R.; ROZENFELD, H. Ecodesign methods focused on remanufacturing. Journal of Cleaner Production, v. 18, p. 21-31, 2010.

RAMID, João. Governo aprova plano de avaliação de impacto ambiental. Revista EXAME. Com. Em 04 de jan 2011.Disponível em: < http://exame.abril.com.br/economia/meio-ambiente-e-

energia/noticias/governo-aprova-plano-de-avaliacao-de-impacto-ambiental >. Acesso em 30 maio de 2012.

ROGERS,Dale S.;TIBBEN-LEMBKE, Ronald S. Going Backwards: Reverse Logistics Trends and Practices. Reverse Logistics Executive Council. University of Nevada, Reno, 1998.

SAMARA, B. S.; BARROS, J. C. Pesquisa de marketing: conceitos e metodologia. 4 ed. São Paulo: Pearson Prentice Hall, 2007.

SARKIS, Joseph. A strategic decision framework for green supply chain management. Journal of Cleaner Production 11, p. 397-409. 2003.

SCHROEDER, R. G.; GOLDSTEIN, S.M.; RUNGTUSANATHAM, M.J. Operations Management contemporary concepts and cases - 5. ed. MacGraw-Hill. Irwin. 2011

SEBRAE. Critérios de classificação de empresas: EI - ME - EPP.2013. Disponível em:

<http://www.sebrae-sc.com.br/leis/default.asp?vcdtexto=4154>. Acesso em 11 jan. 2013.

SHEU, J.B.; CHOU, Y.H.; HU, C.C. An integrated logistics operational model for green-supply chain management.In. Transportation Research Part E. v.41.p. 287-313. 2005

SRIVASTAVA, Samir K. Green supply-chain management: a state-of-the-art literature review.

International Journal of Management Reviews. v. 9, n. 1, p. 53-80, 2007. 